\title{
HIGH RISK FOR CARDIOVASCULAR DISEASE IN POSTMENOPAUSAL BREAST CANCER SURVIVORS
}

\author{
Daniel A. B. Buttros¹, Mauro T. Branco', Benedito S. A. Filho', Jorge Nahás-Neto1, Eliana A. P. Nahás \\ 'Programa de Pós-graduação em Ginecologia, Obstetrícia e Mastologia, Faculdade de Medicina de Botucatu - \\ Botucatu (SP), Brazil.
}

Objective: To evaluate cardiovascular risk factors in postmenopausal women treated for breast cancer compared to postmenopausal women without breast cancer. Methods: A cross-sectional clinical study was performed with 96 postmenopausal women treated for breast cancer compared to 192 postmenopausal women without breast cancer (control) aged 45 to 75 years. Women with amenorrhea $>12$ months, age $\geq 45$ years, and histological diagnosis of breast cancer without distant metastatic disease nor established cardiovascular disease (CVD) were included in the main group. The control group comprised women with amenorrhea $>12$ months, age $\geq 45$ years, without breast cancer nor CVD. The groups were matched by age, time since menopause and body mass index (BMI) in the proportion of 1 case for 2 controls. Clinical and anthropometric data (BMI and waist circumference) were collected. Total cholesterol, HLD, LDL, triglycerides, glucose and insulin levels were measured. Women who presented three or more of the following criteria were diagnosed as having metabolic syndrome (SM): waist circumference (WC)>88 cm; TG $2150 \mathrm{mg} / \mathrm{dL}$; HDL cholesterol <50 mg/dL; blood pressure $\geq 130 / 85 \mathrm{mmHg}$; glucose $\geq 100 \mathrm{mg} / \mathrm{dL}$. For measuring plasma concentrations of HSP 60 and 70, immunoassays by ELISA technique were used. Carotid artery ultrasonography was performed to evaluate the intima-media thickness. For statistical analysis, Student's t-test, Gamma Distribution, Chi-Square Test, and Logistic Regression (odds ratio-OR) were used. Results: Patients with breast cancer had higher levels of HSP 60 and lower HSP 70 when compared to control $(\mathrm{p}<0.05)$. There was a greater prevalence of atheromatous plaque among women treated for breast cancer when compared to the control group ( $19.8 \%$ vs. $9.4 \%$ respectively) $(\mathrm{p}<0.05)$. In the risk analysis adjusted for age, time since menopause and BMI, women treated for breast cancer had a significantly increased risk for MS (OR=4.21, 95\%CI 2.28-7.76), presence of atheromatous plaque (OR=2.61, 95\%CI 1.19-5.72), hypertriglyceridemia ( $\mathrm{OR}=2.32$, 95\%CI 1.33-4.0) and large waist circumference (OR=11.22, 95\%CI 4.0-31.65) when compared to women without breast cancer ( $<<0.05)$. Conclusion: Women treated for breast cancer had a higher risk for metabolic syndrome, diabetes, atherosclerotic disease, hypertriglyceridemia and abdominal obesity, important risk factors for cardiovascular disease when compared to postmenopausal women without breast cancer. 